Proceedings of the 50th Hawaii International Conference on System Sciences | 2017

\title{
The Information Systems Artifact: A Conceptualization Based on General Systems Theory
}

\author{
Sutirtha Chatterjee \\ University of Nevada, Las Vegas, USA \\ sutirtha.chatterjee@unlv.edu \\ Amany Elbanna \\ Royal Holloway University of London, UK \\ Amany.Elbanna@rhul.ac.uk
}

\author{
Xiao Xiao \\ Copenhagen Business School, Denmark \\ xxi.itm@cbs.dk \\ Suprateek Sarker \\ University of Virginia, USA \\ sarkers@,virginia.edu
}

\begin{abstract}
Passionate debates regarding the defining characteristic of the "IT artifact" continue. Such debates, and also the lack of explicit consideration of the "information" element in the IT artifact, motivate us to propose a revised conception, drawing upon concepts from General Systems Theory (GST). Following a number of scholars [39], we name our reconceptualization as an IS artifact, which aims to provide a contemporary view of an IS that could accommodate the changing nature of both society and technology while at the same time maintain a clear definition of what we mean by an IS.
\end{abstract}

\section{Introduction and Research Objective \\ 1.1. The Debate on the Nature of the IT Artifact}

The nature and boundaries of the information systems (IS) field, and in particular the notion of the "IT artifact" 1, continue to occupy IS scholars who argue for its importance in defining who we are and what we research $[8,22,53]$. Historically, the IS field has observed well-known debates regarding the notion of the IT artifact. One debate has centered on whether the IT artifact is a useful conception in the first place. Some IS scholars have argued that the IT artifact represents the essence of IS [8], while others have called for disbanding this notion [5]. As noted by Alter [5], the IT artifact has been so variedly defined, that it has lost much of its usefulness. For example, he argues that the definition of the IT artifact provided at the ICIS 2013 mini-track could be inferred to mean any of "three completely different kinds of things, technologies consisting of hardware and software, sociotechnical systems with human participants, and processes and methods" (p. 47). Such an all-

\footnotetext{
${ }^{1}$ The IT artifact has been broadly defined as "bundles of material and cultural properties packaged in some socially recognizable form such as hardware and/or software."[53, p. 121].
}

encompassing definition, he argues, is not useful because it lacks precision.

The varied definition of the IT artifact is also illustrated by other scholars, who observe that such diverse conceptions create much confusion among IS academics [44]. Part of the problem is also related to how different research/professional groups and academic communities have understood differing ontologies and epistemologies underlying the IT artifact - for example, for some the IT artifact implies only technical artifacts, while for others it also includes social artifacts [5]. Arguably, the problems with the conception of the IT artifact arise from the uniqueness of IS, as lying between "organizational sciences and technical sciences," which allows such varied definitions [28, p. 610].

The other part of the debate on the IT artifact is whether we should even entertain the notion of an IT artifact. Philosophically, IS scholars have argued both for, and against, having a clear and rigid definition of the IT artifact. To some scholars, a clear notion of the IT artifact is essential [8,53], while others doubt the value of such rigid definitions, which, they argue, represent a dominant form of thinking that constricts creativity and intellectual development of the IS field [60]. More recently, some scholars have argued that we should focus on an "IS artifact" instead of an "IT artifact" [39] while other scholars have, in turn, argued that even this notion of an IS artifact is not a useful conception [30].

It is clear therefore, that the notion of the IT artifact is contentious, fuzzy, and excites much passion and debate. Fast changing landscapes in technology and business have further added to this confusion. Especially in today's environment, computing is part of our daily lives and technology has widely and deeply penetrated our society to become ubiquitous [73]. In other words, technologies are embedded and often unobservable [3], leading to difficulties in clearly 
locating the IT artifact. Indeed, a prominent group of scholars have recently argued that, in general, it is becoming increasingly difficult to identify technologies separately from people who use them [51, 52, 54]. In addition, the Analytics and Big Data revolution is fundamentally reforming our notion of the IT artifact by focusing on "information" [2], an aspect which the conception of the IT artifact has traditionally neglected.

In sum, therefore, recent developments clearly illustrate that what we mean by an IT artifact in unsettled and changing [44]. We contend therefore, that the time is ripe for us to try and form a conception of the IT artifact that, while being adaptable to contemporary trends, ensures that IS does not lose connection with its past traditions of research and intellectual development. In particular, this effort to "contemporize" the IT artifact is further necessary given that traditionally the notion of "information"occurring in the very definition of IS, has been sorely neglected in prior research [45].

\subsection{Information: A Missing but Essential Component?}

Recent arguments by IS scholars indicate that information should be a core element when we define an IT artifact [39]. In fact, this is one of the reasons that have led to arguments that we should perhaps morph the IT artifact into an IS artifact [65], an argument that further motivates our research objective in the following section.

This lack of recognition of the "information" limits the relevance of IS, especially with the current need to focus on the "information" aspect in areas such as business intelligence, data analytics, and big data $[2,18]$ (e.g., the MISQ forthcoming special issue on the transformational issues of big data and analytics). Beyond this, researchers today are also progressively engaged with other "information" aspects, such as information ontology and extraction [70], the semantics (and pragmatics) of information representation [9], and the architectural aspects of information [69]. It is therefore, clear that current IS research imparts great importance to the role of information. Similarly, in practice, it has been argued that other than automation, "... what companies value the most about IT is its role in delivering and managing the information that the organization relies on..." [36, p. 842, emphases added]. Indeed, prominent visionaries within the IS discipline have gone so far as to conclude that information presents the core of the IS field [23, 39, 50]

In spite of these acknowledgements, traditionally, information has been inadequately treated in IS literature [45], and often inconsistently defined/understood [10]. This is symptomatic of the traditional oversight of information in IS research and in the conceptions of the IT artifact. Not surprisingly, notable thinkers beyond IS, such as management guru Peter Drucker, have observed this deficiency, saying to a reputed scholar in our discipline (Professor Lynne Markus) that "The problem with your field, is that you haven't figured out that it's about information, not about technology" [27, p. 471]. Indeed as scholars expressed it, "Technologies come and go, but the need for information is persistent and ever increasing." [49, p. 2][emphases added].

Therefore, the importance of having clear and contemporary definition of the IT artifact that accommodates 'information' as a key component cannot be emphasized more. We argue that such a definition should be inclusive, which can both represent what IS traditionally stands for, but also encompass the latest development in the discipline, especially in relation to the role of "information"; and it should also be easily articulated to IS students and the outside community. In this sense, motivated by such clear need, we present our research objective below.

\subsection{Research objective}

Inspired by the above discussions - the debate on the nature of the IT artifact, as well as its neglect of the information aspect, we argue that it is imperative to reconsider how we can conceive of a more contemporary view of the IT artifact, that includes "information" as an entity within the conception of an IS [38, 39]. Our basic contention is that an IT artifact should constitute social, technical, and information elements, and these together should constitute the "information system" [31]. We are also inspired by recent critiques of the IT artifact that argue that the IT artifact has traditionally focused on the technology and the social aspects surrounding it, thus leaving out a key component which by definition is part of an IS"information"[39]. Addressing this necessitates moving from an IT artifact to an IS artifact [39], a motivation that guides our paper:

$R Q$ : How we conceive a more contemporary view of the IT artifact (which we shall call the IS artifact), which ascribes, among others, a key role to information?

To answer the research question, this paper offers a conceptual formulation of the IS artifact. Constructs from the General Systems Theory (GST) are applied to support the development of a framework that suits the changing nature of IS and accounts for information as a constitutive part of IS [17]. Indeed, recent research has conceptualized a system-theoretic view of the "IT artifact" [44]. Our work is inspired by such research, but moves it forward to apply GST to formulate an IS 
artifact instead of an IT artifact.

\section{General systems theory}

There are obviously different ways to visit the IS artifact - we present one possible way forward using the framework of General Systems Theory [66]. Our goal is to renew the traditional conceptions of IS such that it continues to embrace a diversity of perspectives and stays in touch with its past traditions, while also being able to integrate with, and adjust to the needs of the future.

So, where do we start to conceive of an IS artifact? Our starting point is based on the label "information systems," which explicitly aligns "information" with "systems" thinking. After all, we are the $I S$ discipline, and therefore, it is natural to align classical notions of IS with an emphasis on "information" and a "systems" view $[38,39]$.

To this end, our point of departure is to develop the "systems" aspect of IS, given that it is one of the important roots of IS, occurring in its very label [23]. In this context, it is helpful to heed to the call for a reintroduction of systems concepts to better understand what an IS means [38]. This would be in line with the "IS discipline's espoused position that it is a discipline about information systems" [38, p. 345]. There have been calls to IS researchers to build upon welldeveloped systems concepts in General Systems Theory or GST $[12,66]$; such calls add that a return to GST is beneficial to the discipline's identity and existence:

"Actually using systems concepts, among other things, could play a major part in contributing to distinguishing the IS discipline and thereby justify its existence. Ultimately, the IS discipline needs to employ systems concepts to a greater extent than it already has" [38, p. 345].

In fact, it should be noted that the IS often "take[s] the concepts and metaphors of general systems theory...."[67, p. 480]. We therefore argue that GST is an appropriate framework if we need to revisit and expand our notion of the IS artifact. Further, as Lee [38] argues, it will help IS scholars signal their distinctive image to other disciplines in business and beyond.

While GST has often been criticized for being overtly mathematical, reductionist, instrumental, and devaluing social factors [66], there have been humanistic trends in GST (ibid) that may be leveraged by IS researchers, given that social relevance is often key to understanding IS phenomena. Indeed, IS researchers have demonstrated that GST can accommodate different paradigms (i.e. both instrumental/mechanistic and humanistic), and it provides a powerful lens to analyze a range of phenomena involving humans and technology [57].
The intellectual range of GST is succinctly captured below:

“... the systems perspective can be implemented in many ways...[from]...hard, mechanistic, closed, and relatively predictable to those that assume that systems are soft, organic, open, and inherently unpredictable ... a systems perspective can underpin a wide variety of research" [14, $\mathrm{p}$. 669].

Given our efforts to formulate a GST-inspired IS artifact, so that it captures the current state of IS research in all its diversity (e.g., different conceptions of IS, as well as the inclusion of information), our turn to GST is thus natural and justifiable.

\section{A revised conception of the IS artifact using GST}

Our objective necessitates a review of the basic GST concepts as summarized in Table $1[1,12,34]$; we draw upon and amalgamate these concepts, as we present our adapted view of an IS artifact (Figure 1). Essentially, in this notion, the IS artifact is represented as a superordinate system composed of the social, technical, and information subsystems.

While there exist well-known definitions of the social and technical subsystems [4], the information subsystem needs to be defined. First, we would like to formally define the information subsystem as conceptually including the data, analytical models (processing interrelationships in the data), as well as the presentation of the data itself, by the social subsystem, the technological subsystem, or a combination of these two subsystems [32]. Further, it is noted that all subsystems (information, social, and technical) are malleable, with fluid and permeable boundaries and emerge with changing contextual conditions and mechanisms [72]. In other words, the subsystems are open systems [74] that interact and engage in exchanges with other subsystems. This interaction focuses on creating dynamic equilibrium with other subsystems in a loosely coupled manner [25].

While we present the basic GST concepts in Table 1 , we found it more parsimonious to combine these concepts into certain basic meta-principles that elaborate how the three subsystems (social, technical, and information) should work together to result in a wholesome concept of the IS artifact. This is because many of these GST concepts are logically related, and utilizing them simultaneously under the same metaprinciple adds parsimony, coherence, as well as incisiveness to our approach.

\subsection{Meta-principle 1}


The IS artifact is composed of interrelated and permeable subsystems combined in a holistic and synergistic manner. In line with the holistic and synergistic idea of systems [34], we contend that there should be a focus on how the three interrelated subsystems combine to synergistically add value in the form of a superordinate system (i.e. the IS artifact).

Nevo and Wade [48], define synergy as positive emergent capabilities such as those "between an IT asset and an organizational resource" that "results in a system [named]...IT-enabled resource" (p. 169, emphasis added). In the IT strategy domain, for example, the notion of synergy has been particularly useful because concepts like IT business value (an example of a holistic system) emerge from the synergy of IT capabilities (technical subsystem) and absorptive capacity (which combines the social, as well as informational subsystems) [59].

This synergism is promoted by permeable boundaries of the subsystems. In order to achieve overall synergy, the subsystems should adapt and exchange subsystem resources through the subsystem boundaries. If the subsystems have closed boundaries (meaning they never import or export resources), then they can never change and adapt; consequently, achieving synergy by combining the subsystems would be

impossible.

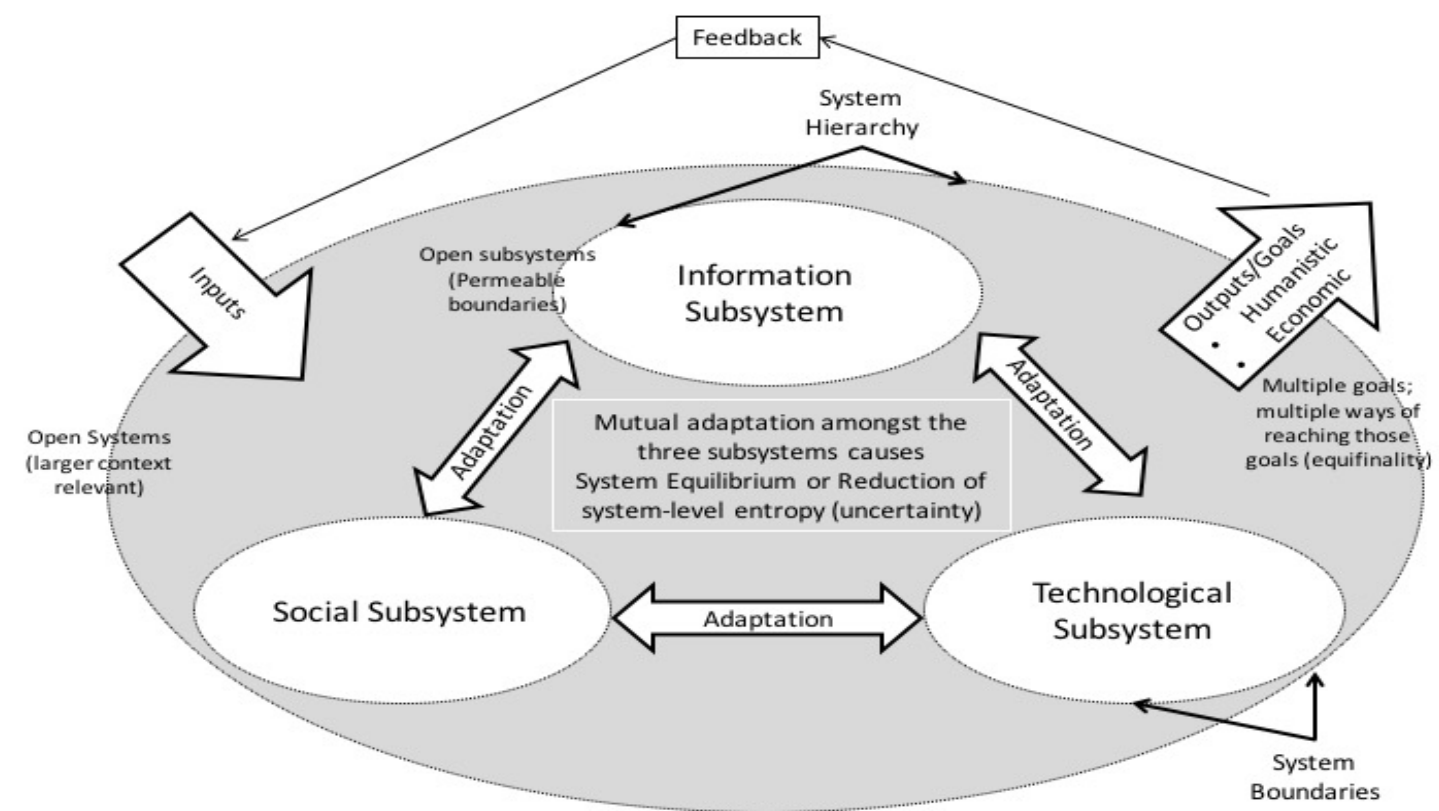

Figure 1: A GST-informed Conception of an IS Artifact ${ }^{2}$

\begin{tabular}{|l|l|}
\hline \multicolumn{1}{|c|}{ Concept } & \multicolumn{1}{c|}{ Table 1. Key concepts of General Systems Theory } \\
\hline Subsystems & $\begin{array}{l}\text { "A system is composed of interrelated parts of elements... Every system has at least two elements, and } \\
\text { these elements are interconnected" }\end{array}$ \\
\hline Hierarchy & "A system is composed of subsystems of a lower order and is also part of a supra-system." \\
\hline Holism/synergism & $\begin{array}{l}\text { "The whole is not just the sum of the parts [subsystems]; the system itself can be explained only as a } \\
\text { totality." }\end{array}$ \\
\hline $\begin{array}{l}\text { Input- } \\
\text { transformation- } \\
\text { output }\end{array}$ & $\begin{array}{l}\text { "The open system can be viewed as a transformation model. In a dynamic relationship with its } \\
\text { environment, it receives various inputs, transforms these inputs in some way, and exports outputs." }\end{array}$ \\
\hline Open systems & "Open systems exchange information, energy, or material with their environments" \\
\hline Multifinality & "Systems have multiple goals and purposes" \\
\hline System boundaries & "Systems have boundaries which separate them from their environment" \\
\hline $\begin{array}{l}\text { Dynamic } \\
\text { equilibrium }\end{array}$ & $\begin{array}{l}\text { "Open systems can attain a status of dynamic equilibrium through the continuous inflow of materials, } \\
\text { energy, and information" }\end{array}$ \\
\hline
\end{tabular}

\footnotetext{
${ }^{2}$ Certain elements of this figure are inspired by Lee et al.[39]
} 


\begin{tabular}{|l|l|}
\hline Equifinality & "Certain results may be achieved with different initial conditions and in different ways" \\
\hline Negative entropy & "A process of more complete organization and ability to transform resources" \\
\hline Feedback & $\begin{array}{l}\text { "Information concerning the outputs or the process of the system is fed back as an input into the system, } \\
\text { perhaps leading to changes in the transformation process and/or future outputs" }\end{array}$ \\
\hline
\end{tabular}

Therefore, the synergistic existence of the superordinate system (i.e. the IS artifact) requires this permeability across the various subsystems [42]. For example, in an IS innovation system, the technical subsystem acts both as a target and engine of innovation by enhancing the permeability of knowledge across system boundaries (e.g. between the social and the information subsystems), allowing knowledge epitomized by the information subsystem to be shared and distributed (using the technological subsystem) for dynamic learning across social structures in an organization [11].

The synergy may also be created through the concept of hierarchical subsystems in GST [34]. For example, the superordinate system could be germane to the system of IT-enabled organizational decision making which incorporates humans processing information, as well as digital controls [40]. The superordinate system could also ascribe greater importance to any of the subsystems (e.g. greater human autonomy or greater reliance on the technology), thus creating an inherent hierarchy [63]. During the life of such superordinate systems, different subsystems may change in hierarchy, so as to contribute to the overall synergy. For example, in the case of ubiquitous computing, technology is often in the context/ background [73]; this apparent relegation in the hierarchy (from an explicit subsystem to a context) promotes the synergy and allows us to accept technology-in-context (in some cases) as a valid form of the IS artifact.

\subsection{Meta-principle 2}

IS artifact comprises of a purposive system that seeks multiple goals through multiple paths (multifinality and equifinality). A purposive, multigoal seeking system is one which can produce the same outcome in different ways (equifinality) as well as lead to different outcomes (multifinality) [1]. An example of equifinality is how two different social structures (CIO-CFO/CIO-CEO) combined with strategic positioning (e.g. information structure signaled to the outside world) may result in technological outcomes such as the acquisition of new IT tools and services [6].

Regarding multifinality, Chaturvedi, et al. [16] note how data on different trends (information subsystem), user needs (social subsystem), and technical models (technical subsystem) produce multiple outcomes for virtual world systems. Multifinality could be instrumental goals related to profit, performance improvement, strategic advantage, value creation, or could be humanistic goals related to societal benefits, human welfare, and achieving equality. However, this multifinality is contingent upon other structural, processual, and/or causal mechanisms [29]; it evolves longitudinally, and may not necessarily be simultaneous [16]. This provides flexibility in the pursuit of multiple (i.e. both humanistic and instrumental) goals which may be satisfied over time.

\subsection{Meta-principle 3}

IS artifact is best represented by an open system. According to our perspective, the superordinate system can be considered as a classic example of an open system, as it is itself a collection of open subsystems, which can survive by importing more energy (inputs) from the environment than they export [56]. For example, environmental turbulence (i.e. an environmental input) is faced by organizations who then counter it by developing improvisational capabilities using the IT infrastructure (technical subsystem) as well as organizational knowledge bases (information subsystem) [55].

An important consideration here is the feedback loop where outputs feedback into the inputs so as to correct deviances from what is desired in the outputs. The idea of feedback is important to achieve both system stability and transformation [34]. Negative feedback will allow for the correction of deviances so that the system does not become unstable; while positive feedback can have a spiraling effect for system improvement. For example, in the context of an IT services supply chain business model [41], feedback control schemes "can improve costs, utilization and stability of workforce ... [and] can produce desirable policies of workforce resource management" (p. 77).

\subsection{Meta-principle 4}

The IS artifact is composed of mutually adaptable subsystems for promoting dynamic equilibrium and reduced entropy. We conceive the three subsystems as mutually adaptable and changing, and recommend that IS researchers recognize the interrelationship among the subsystems and the implications of such inter-relationships for the system as a whole. The core focus of the subsystems through this mutual adaptation is to reduce overall entropy of the superordinate system. Entropy (of a system) measures the degree to which a system is disorganized 
[61] - in such a system, the outcomes are random and therefore information about the outcomes is completely uncertain [45]. Put in another way, entropy captures how random and uncertain a system is.

The value of the concept of entropy is illustrated by Mingers and Walsham [46] who argue, based on Floridi's conception of information objects [21], that such information objects are "entitled to a degree of moral value of respect" (p. 838). Interpreting it in our context, we can argue that the social and the technical subsystems should not violate this entitlement of the information subsystem - any such violation would increase the entropy of the system [46]. For example, if the human beings misappropriate/misuse information in organizational knowledge bases (and technical controls are not built in to prevent these), it would raise the entropy of the organizational security system [7]. Other researchers also allude to the need for lowering entropy, viewing "resonance" between human users (social subsystem) and technological aspects (technical subsystem) as a way to reduce entropy [19].

\section{Discussion: Materializing the IS artifact in an IS}

The GST-based formulation of an IS artifact, that, arguably, is flexible, yet tangible enough, emerges as a possible solution to the debates regarding the nature of the IT artifact. Notably, the IS artifact is more relevant to define the essence of an IS because of its ability to balance rigidity and flexibility. A completely rigid definition of the IS artifact is problematic, as is a completely flexible one.

The meta-principles of the IS artifact give rise to normative considerations that need to be satisfied in order for the IS artifact to be faithfully captured into an IS. These follow from the meta-principles discussed before, and arguably, define what an IS is.

\subsection{An IS should promote holistic synergy among the constituent subsystems}

We argue that an IS should be characterized by whether the overall synergy for the superordinate system is attained. Notably, we conceive that in an IS, each subsystem is important insofar as it contributes to the overall synergy. Thus, if one subsystem "takes control" over another (a hierarchy), so as to increase synergy in the superordinate system, it would be consistent with our (revised) interpretation of IS. Consider the earlier example of IT-enabled organizational decision-making, which can be considered representing the superordinate IS artifact [40]. It could well happen that human beings assume greater autonomy and overrule recommendations of the technology (i.e. the social controlling the technical). Or, it could also happen that technology has the final say and users follow the recommendations made by the technology faithfully.

Further, each of these subsystems has permeable boundaries to incorporate interactions from other systems. What this implies is that the technology can subdued into the user, i.e. the technical subsystem has penetrated inside the social subsystem, in part due to the "permeable" boundaries that the social subsystem provides [73]. It could be the other way round, where the social can penetrate into the technology through inscriptions of human values [15]. Obviously accepting such interpenetration and permeability is necessary, if, for example, we are to assume that ubiquitous computing technologies and their users form a valid form of IS.

4.2 In an IS, the social, technical, and information subsystems should support each other

Echoing the criticism by the sociomaterial scholars that separate components of an IS may not always interact explicitly [52], we contend that we should focus on mutual support between the three subsystems. For example, Jones [33] notes how patients depend on support from ventilators in order to survive. Similarly, Reinecke and Bernstein [58] propose designing technologies that support cultural adaptivity. The IS failures literature [43] is replete with examples where users stopped using the IT (technical subsystem) because it was causing disruptive effects and increasing organizational entropy.

In many of these instances, one or more of the subsystems (e.g. the technical one), is supporting another (e.g. the social one, or the information one), irrespective of whether they interact or not. In fact, in the many examples of IS failures in the literature, one subsystem is prevented from interacting/interfering with another, thus indicating the "support." Especially, if subsystems are in an irreconcilable conflict [71], support might involve removing one of the disruptive subsystems to ensure stability; focusing on interaction (instead of support) will lead to a path of chaos. We emphasize that interaction can be negative (e.g. harmful) and increase entropy, but support always has a positive connotation, increasing the system synergy and reducing entropy through better subsystem alignment [48]. Consequently, we see support across subsystems as a meaningful requirement for understanding what an IS is.

\subsection{In an IS, entropy should be reduced}

Continuing on from the previous discussion, we believe that it is more useful to focus on how each subsystem contributes to support other subsystems so 
as to reduce the overall entropy of the superordinate system. The lesser the entropy, the more "ordered" and "organized" the superordinate system (IS) is.

Entropy is of importance because "systems that consist of a large number of interacting elements [i.e. subsystems] can display self-organizing [i.e. entropy-reducing] behavior" [47, p. 283]. Toh and Kim [62] provide an example of this, noting that in situations of high technological entropy (uncertainty about technological innovations and investments), organizations may tend to invest more in the technology so as to alleviate this uncertainty and stabilize the system.

In our conception, therefore, a focus on entropy of the overall IS is paramount, because in the end, that will stabilize the system. For example, in the context of online communication system (example of an IS), we should focus on how to reduce overall entropy in the system and move it toward maturity and stability [24].

\subsection{In an IS, equifinality and multifinality should emerge over time.}

We believe our revised understanding of IS offers an avenue of pursuing many kinds of outcomes, both instrumental and humanistic. Instrumental outcomes could be for example, greater revenues, and humanistic outcomes could be more along the lines of employee satisfaction or quality of work life. The GST concepts of equifinality and multifinality allow us to accommodate such varying outcomes of an IS. For example, it is important to understand that multifinality for a system evolves longitudinally [68], and it is often the case that multiple goals are not pursued or achieved simultaneously. Thus, it is meaningful to investigate if one set of goals (say, economic) could lead, in time, to another set of goals (say, humanistic), or vice versa.

We could also investigate how goals are being continually negotiated, and thus emergent; therefore it may happen that the multifinality that we finally achieve is quite different from the multifinality we aimed for [71]. In short, we need to consider the "big picture" and focus on the temporal emergence of such multiple goals, as well as the different paths that emerge to reach those goals. In pursuit of this temporal emergence, the feedback mechanism is arguably crucial. The feedback mechanism introduces a temporal order where the multiple goals may follow one another in sequence [41]. Apart from helping us achieve multifinality, the feedback mechanism also illuminates on different paths to achieve the same goal [75] - thereby upholding equifinality.

\section{Contribution and Implications}

This paper contributes by revisiting the notion of an IS artifact, ultimately providing concrete implications of what we can mean by an IS [20]. Two contributions of the paper are evident: one, a clear inclusion of "information" within the definition of IS, and two, articulating a more relevant perspective of IS, that arguably addresses much of the confusion and debate regarding the IT artifact. In this paper, we observe that the IS artifact is perhaps more appropriate as a basis of IS research than the IT artifact.

While information is the central artifact of the IS community [22], our review captures that it has often been inadequately addressed in the IS literature [45]. Furthermore, the few attempts at conceptualizing information have often been inconsistent. For example, while Langefors' infological model [37] has been quite popular, it has also been criticized in recent research, most notably due to its lack of precision in conceptualizing knowledge and its relation to information and data, and its tendency to still define information in terms of a system of data without any particular relation to knowledge [35]. In fact, researchers note various inconsistencies in how information has been defined across various studies [10]:

- Information is data that is selected and assumes meaning and relevance in a context and purpose [17].

- Information is making knowledge explicit [64]

- Information results from the application of knowledge to data [35].

As we can see, such competing concepts often create confusion in the minds of IS academics and others. By explicitly acknowledging information as a valuable component of IS, we stimulate IS researchers to address this issue head-on, and arrive at a clear definition of what we mean by "information" especially within the context of phenomena investigated by IS researchers. We also should highlight that we provide a concrete definition of what we perceive to be the information subsystem; however, this definition is open to debate and we invite our IS colleagues to modify our conception to arrive at a greater consensus. Therefore, hopefully, our paper serves as a wake-up call to our IS colleagues and move us closer to a more accurate and consensual definition of information. Our paper establishes the fact that without clearly defining "information," we will never be clear about what an IS is.

Beyond the explicit consideration of information, we feel that that our paper also contributes by illuminating the various forms of IS that could exist in today's technological and business landscape. For example, while IS has three components, not all of them may be equally explicit in a particular context. According to our conception, an IS could have the 
three components assuming equal importance, or could also be understood as one where one or two of the three subsystems predominates, possibly with some contextualization/background recognition of the other subsystems. So, for example, if technology needs to be the context (e.g. ubiquitous computing), it would be considered a legitimate form of IS. Similarly, if a technical subsystem is dominant and in the foreground (e.g., in the design of efficient web-retrieval algorithms) with user satisfaction due to lower response times as the background motive, it should be considered legitimate form of IS as well. As long as a background that is explicitly absent, yet adds more meaning to the more explicit components (e.g. efficient algorithms are meaningful because they help user satisfaction), it should qualify as a valid form of IS.

Consider, for example, the concept of system entropy. While entropy could be reduced by eschewing one subsystem (e.g. technology, as in the IS failures example), it could also be reduced by bringing in the social, the technical, and the information subsystems synergistically together. Both are valid forms of IS. As an illustration of the latter, we see how the permeability of the subsystems allows for people and information to interact [13] and the technical subsystem can accordingly adapt to this interaction to allow for the better building of an IS of IT-enabled organizational resources [26]. In other words, while reformulation of an IS artifact leads us to be mindful that the proposed redefinition should neither be constricting - such that potential outside stakeholders are prevented to engage in IS research - nor should it be so amorphous that we have difficulty explaining what IS is to a possible stakeholder outside the immediate IS community.

Notably, the broad and flexible framework of GST, which we have used to develop our contemporary view of the IS artifact, helps us in this objective. GST is open to multiple ontological and epistemological positions, and hence, to different methodological approaches. In this regard, GST is truly unique in that it can support mechanistic, positivistic, deterministic, and causal inquiries, as well as interpretive inquiries that are essentially organic, non-deterministic, and emergent [14]. Further, GST promotes crossdisciplinary scholarship, often through the use of novel methodological approaches including, and beyond, those of pure science [66]. This, we believe, is altogether consistent with our view of IS as enabling the spirit of inclusiveness and diversity.

To conclude, we hope that we have raised relevant issues related to the nature of the IS artifact, and accordingly the nature of an IS. We hope that our proposed GST-based view will stimulate further discussions within the community, resulting in a clear consensus of what an IS is. We believe that such conversation will help move the discipline forward by ensuring its uniqueness and relevance in the everchanging environment.

\section{References}

[1] Ackoff, R.L. Towards a system of systems concepts. Management science, 17, 11 (1971), 661-671.

[2] Agarwal, R. and Dhar, V. Editorial-big data, data science, and analytics: The opportunity and challenge for is research. Information systems research, 25, 3 (2014), 443448.

[3] Agarwal, R. and Tiwana, A. Editorial-evolvable systems: Through the looking glass of is. Information Systems Research, 26, 3 (2015), 473-479.

[4] Alter, S. Work system theory: Overview of core concepts, extensions, and challenges for the future. Journal of the Association for Information Systems, 14, 2 (2013), 72-121.

[5] Alter, S. The concept of 'it artifact'has outlived its usefulness and should be retired now. Information Systems Journal, 25, 1 (2015), 47-60.

[6] Banker, R.D.; Hu, N.; Pavlou, P.A.; and Luftman, J. Cio reporting structure, strategic positioning, and firm performance. MIS Quarterly, 35, 2 (2011), 487-504.

[7] Baskerville, R. The second-order security dilemma. Information Technology and Changes in Organizational Work, (1995), 239-249.

[8] Benbasat, I. and Zmud, R.W. The identity crisis within the is discipline: Defining and communicating the discipline's core properties. MIS quarterly, (2003), 183-194.

[9] Bera, P.; Burton-Jones, A.; and Wand, Y. Research note-how semantics and pragmatics interact in understanding conceptual models. Information systems research, 25, 2 (2014), 401-419.

[10] Boell, S. and Cecez-Kecmanovic, D. What is 'information'beyond a definition? Presented at International Conference on Information Systems, Fort Worth, TX, 2015.

[11] Boland, R.J.; Lyytinen, K.; and Yoo, Y. Wakes of innovation in project networks: The case of digital 3-d representations in architecture, engineering, and construction. Organization Science, 18, 4 (2007), 631-647.

[12] Boulding, K.E. General systems theory-the skeleton of science. Management science, 2, 3 (1956), 197-208.

[13] Bresman, H. and Zellmer-Bruhn, M. The structural context of team learning: Effects of organizational and team structure on internal and external learning. Organization Science, 24, 4 (2013), 1120-1139.

[14] Burton-Jones, A.; McLean, E.R.; and Monod, E. Theoretical perspectives in is research: From variance and process to conceptual latitude and conceptual fit. European Journal of Information Systems, 24, 6 (2015), 664-679.

[15] Chatterjee, S.; Sarker, S.; and Fuller, M.A. A deontological approach to designing ethical collaboration. 
Journal of the Association for Information Systems, 10, 3 (2009a),

[16] Chaturvedi, A.R.; Dolk, D.R.; and Drnevich, P.L. Design principles for virtual worlds. Mis Quarterly, 35, 3 (2011), 673-684.

[17] Checkland, P.B. and Holwell, S.E. Data, capta, information and knowledge. In M. Hinton (ed.), Introducing information management: The business approach. London: Elsevier, 2006, pp. 47-55.

[18] Chen, H.; Chiang, R.H.; and Storey, V.C. Business intelligence and analytics: From big data to big impact. MIS Quarterly, 36, 4 (2012), 1165-1188.

[19] El Sawy, O.A. The is core ix: The 3 faces of is identity: Connection, immersion, and fusion. Communications of the Association for Information Systems, 12, 1 (2003), 39.

[20] Elbanna, A. and Newman, M. The rise and decline of ethics methodology of systems implementation: Lessons for is research. Journal of Information Technology, 28, (2013), 124-136.

[21] Floridi, L. What is the philosophy of information? Metaphilosophy, 33, 1-2 (2002), 123-145.

[22] Galliers, R.D. Change as crisis or growth? Toward a trans-disciplinary view of information systems as a field of study: A response to benbasat and zmud's call for returning to the it artifact. Journal of the Association for Information Systems, 4, 1 (2003), 13.

[23] Galliers, R.D. Change as crisis or growth? Toward a trans-disciplinary view of information systems as a field of study: A response to benbasat and zmud's call for returning to the it artifact. Journal of the Association for Information Systems, 4, 6 (2003), 337-351.

[24] Godes, D. and Mayzlin, D. Using online conversations to study word-of-mouth communication. Marketing Science, 23, 4 (2004), 545-560.

[25] Gulati, R.; Sytch, M.; and Tatarynowicz, A. The rise and fall of small worlds: Exploring the dynamics of social structure. Organization Science, 23, 2 (2010), 449-471.

[26] Han, K. and Mithas, S. Information technology outsourcing and non-it operating costs: An empirical investigation. Mis Quarterly, 37, 1 (2013), 315-331.

[27] Hassan, N.R. Is information systems a discipline?; foucauldian and toulminian insights. European Journal of Information Systems, 20, 4 (2011), 456-476.

[28] Hassan, N.R. Paradigm lost... paradigm gained: A hermeneutical rejoinder to banville and landry's 'can the field of mis be disciplined\&quest;'. European Journal of Information Systems, 23, 6 (2014), 600-615.

[29] Henfridsson, O. and Bygstad, B. The generative mechanisms of digital infrastructure evolution. Mis Quarterly, 37, 3 (2013), 907-931.

[30] Iivari, J. Information system artefact or information system application: That is the question. Information Systems Journal, Forthcoming, Forthcoming (2016),
[31] Ives, B.; Hamilton, S.; and Davis, G.B. A framework for research in computer-based management information systems. Management science, 26, 9 (1980), 910-934.

[32] Ives, B.; Hamilton, S.; and Gordon, B.D. A framework for research in computer-based management information systems. Management science, 26, 9 (1980), 910-934.

[33] Jones, M. A matter of life and death: Exploring conceptualizations of sociomateriality in the context of critical care. Mis Quarterly, 38, 3 (2014), 895-925.

[34] Kast, F.E. and Rosenzweig, J.E. General systems theory: Applications for organization and management. Academy of Management Journal, 15, 4 (1972), 447-465.

[35] Kettinger, W.J. and Li, Y. The infological equation extended: Towards conceptual clarity in the relationship between data, information and knowledge. European Journal of Information Systems, 19, 4 (2010), 409-421.

[36] Kettinger, W.J.; Zhang, C.; and Chang, K.-C. Research note- a view from the top: Integrated information delivery and effective information use from the senior executive's perspective. Information systems research, 24, 3 (2013), 842860 .

[37] Langefors, B. Infological models and information user views. Information Systems, 5, 1 (1980), 17-32.

[38] Lee, A.S. Retrospect and prospect: Information systems research in the last and next 25 years. Journal of Information Technology, 25, 4 (2010), 336-348.

[39] Lee, A.S.; Thomas, M.; and Baskerville, R.L. Going back to basics in design science: From the information technology artifact to the information systems artifact. Information Systems Journal, 25, 1 (2015), 5-21.

[40] Lee, J. and Berente, N. Digital innovation and the division of innovative labor: Digital controls in the automotive industry. Organization Science, 23, 5 (2011), $1428-1447$.

[41] Lee, Y.M.; An, L.; and Connors, D. Application of feedback control method to workforce management in a service supply chain. Service Science, 1, 2 (2009), 77-92.

[42] Lomi, A.; Lusher, D.; Pattison, P.E.; and Robins, G. The focused organization of advice relations: A study in boundary crossing. Organization Science, 25, 2 (2013), 438-457.

[43] Lyytinen, K. and Hirschheim, R. Information systems failures: A survey and classification of the empirical literature. Oxford surveys in information technology, 4, 1 (1987), 257-309.

[44] Matook, S. and Brown, S.A. Characteristics of it artifacts: A systems thinking-based framework for delineating and theorizing it artifacts. Information Systems Journal, Forthcoming, Forthcoming (2016),

[45] McKinney Jr, E.H. and Yoos, C.J. Information about information: A taxonomy of views. Mis Quarterly, 34, 2 (2010), 329-344.

[46] Mingers, J. and Walsham, G. Toward ethical information systems: The contribution of discourse ethics. Mis Quarterly, 34, 4 (2010), 833-854. 
[47] Morel, B. and Ramanujam, R. Through the looking glass of complexity: The dynamics of organizations as adaptive and evolving systems. Organization Science, 10, 3 (1999), 278-293.

[48] Nevo, S. and Wade, M.R. The formation and value of itenabled resources: Antecedents and consequences. Management Information Systems Quarterly, 34, 1 (2010), 10 .

[49] Nunamaker, J.F. and Briggs, R.O. Toward a broader vision for information systems. ACM Trans. Manage. Inf. Syst., 2, 4 (2011), 1-12.

[50] Nunamaker, J.F.; Briggs, R.O.; Derrick, D.C.; and Schwabe, G. The last research mile: Achieving both rigor and relevance in information systems research. Journal of Management Information Systems, 32, 3 (2015), 10-47.

[51] Orlikowski, W.J. Sociomaterial practices: Exploring technology at work. Organization studies, 28, 9 (2007), $1435-1448$

[52] Orlikowski, W.J. The sociomateriality of organisational life: Considering technology in management research. Cambridge Journal of Economics, 34, 1 (2010), 125-141.

[53] Orlikowski, W.J. and Iacono, C.S. Research commentary: Desperately seeking the" it" in it research-a call to theorizing the it artifact. Information systems research, 12,2 (2001), 121-134.

[54] Orlikowski, W.J. and Scott, S.V. Sociomateriality: Challenging the separation of technology, work and organization. The Academy of Management Annals, 2, 1 (2008), 433-474.

[55] Pavlou, P.A. and El Sawy, O.A. The "third hand": Itenabled competitive advantage in turbulence through improvisational capabilities. Information systems research, 21, 3 (2010), 443-471.

[56] Peery, N.S. General systems theory: An inquiry into its social philosophy. Academy of Management Journal, 15, 4 (1972), 495-510.

[57] Porra, J.; Hirschheim, R.; and Parks, M.S. The history of texaco's corporate information technology function: A general systems theoretical interpretation. Management Information Systems Quarterly, 29, 4 (2005), 721-746.

[58] Reinecke, K. and Bernstein, A. Knowing what a user likes: A design science ap-proach to interfaces that automatically adapt to culture. Mis Quarterly, 37, 2 (2013), 427-453.

[59] Roberts, N.; Galluch, P.S.; Dinger, M.; and Grover, V. Absorptive capacity and information systems research: Review, synthesis, and directions for future research. Mis Quarterly, 36, 2 (2012), 625-648.

[60] Robey, D. Identity, legitimacy and the dominant research paradigm: An alternative prescription for the is discipline: A response to benbasat and zmud's call for returning to the it artifact. Journal of the Association for Information Systems, 4, 1 (2003), 15.
[61] Swanson, G.A.; Bailey, K.D.; and Miller, J.G. Entropy, social entropy and money: A living systems theory perspective. Systems Research and Behavioral Science, 14, 1 (1997), 45-65.

[62] Toh, P.K. and Kim, T. Why put all your eggs in one basket? A competition-based view of how technological uncertainty affects a firm's technological specialization. Organization Science, 24, 4 (2013), 1214-1236.

[63] Tuertscher, P.; Garud, R.; and Kumaraswamy, A. Justification and interlaced knowledge at atlas, cern. Organization Science, 25, 6 (2014), 1579-1608.

[64] Tuomi, I. Data is more than knowledge. Journal of Management Information Systems, 16, 3 (1999), 107-121.

[65] Vartiainen, T. and Tuunanen, T. Value co-creation and co-destruction in an is artifact: Contradictions of geocaching. Presented at 2016 49th Hawaii International Conference on System Sciences (HICSS), 2016, pp. 1266-1275.

[66] Von Bertalanffy, L. The history and status of general systems theory. Academy of Management Journal, 15, 4 (1972), 407-426.

[67] Walker, G.H.; Stanton, N.A.; Salmon, P.M.; and Jenkins, D.P. A review of sociotechnical systems theory: A classic concept for new command and control paradigms. Theoretical Issues in Ergonomics Science, 9, 6 (2008), 479499.

[68] Wasko, M.; Teigland, R.; Leidner, D.; and Jarvenpaa, S. Stepping into the internet: New ventures in virtual worlds. Mis Quarterly, 35, 3 (2011), 645-652.

[69] Williams, C.K. and Karahanna, E. Causal explanation in the coordinating process: A critical realist case study of federated it governance structures. Mis Quarterly, 37, 3 (2013), 933-964.

[70] Wimalasuriya, D.C. and Dou, D. Ontology-based information extraction: An introduction and a survey of current approaches. Journal of Information Science, (2010),

[71] Winter, S.; Berente, N.; Howison, J.; and Butler, B. Beyond the organizational 'container': Conceptualizing 21st century sociotechnical work. Information and Organization, 24, 4 (2014), 250-269.

[72] Wynn Jr, D. and Williams, C.K. Principles for conducting critical realist case study research in information systems. MIS Quarterly, 36, 3 (2012), 787-810.

[73] Yoo, Y. Computing in everyday life: A call for research on experiential computing. MIS Quarterly, 34, 2 (2010), 213231.

[74] Zachariadis, M.; Scott, S.; and Barrett, M. Methodological implications of critical realism for mixedmethods research. Mis Quarterly, 37, 3 (2013), 855-880.

[75] Zollo, M. and Winter, S.G. Deliberate learning and the evolution of dynamic capabilities. Organization Science, 13, 3 (2002), 339-351. 